\title{
ИЗУЧЕНИЕ ЗДОРОВЬЯ: \\ ПОТЕНЦИАЛ ПЕРЕПИСЕЙ НАСЕЛЕНИЯ
}

\author{
АЛЕКСАНДР РАМОНОВ, АНАСТАСИЯ ПЬЯНКОВА
}

\begin{abstract}
В статье рассмотрены ключевые подходы к изучению нездоровья и инвалидности, принятые в зарубежной и российской исследовательской практике. Показана плодотворность «новой» концепции определения нездоровья и инвалидности, понимаемых как ограничения в жизнедеятельности и социальном взаимодействии в связи с нарушениями функций организма. На основе систематизации международного опыта измерения нездоровья и инвалидности с помощью переписей и репрезентативных опросов населения предложены инструменты по измерению их распространенности в России. В частности, с целью получения более интересных и практически полезных результатов, разработан подробный инструментарий для измерения здоровья на основе микропереписи населения РФ с учетом рекомендаций международных организащий (ВОЗ и ООН).
\end{abstract}

Ключевые слова: перепись населения, здоровье, инвалидность.

\section{ИМЕЕТ ЛИ СМЫСЛ ЗАДАВАТЬ ВОПРОСЫ О ЗДОРОВЬЕ В ПЕРЕПИСИ НАСЕЛЕНИЯ?}

Информация о состоянии здоровья населения необходима для того, чтобы судить о его социальном благополучии, а кроме того, имеет большое прикладное значение. Она может быть использована для определения приоритетов социальной политики и распределения ресурсов системы здравоохранения, определения границ возраста окончания трудовой активности и форм помощи людям с продолжительными ограничениями в базовых видах активности.

Сейчас информация о здоровье населения России носит фрагментарный и неполный характер, что не соответствует рекомендациям ведущих международных организаций [ООН 2009]. Отсюда актуальность расширения источников информации о здоровье. Один из возможных путей решения этой задачи - включение вопросов о здоровье в программу переписей населения.

Полученная таким образом информация о здоровье может иметь множество практических результатов, начиная от определения и планирования объемов и структуры спроса на специальные устройства (например, инвалидные кресла) и социальную помощь (сиделки, няни) для определенных групп населения [Mishra, Gupta 2006] и заканчивая разработкой региональных программ, направленных на снижение неравенства по уровню здоровья и смягчение его последствий [Lezzoni 2011].

\footnotetext{
РАМОНОВ АЛЕКСАНДР ВЛАДИМИРОВИЧ, ИНСТИТУТ ДЕМОГРАФИИ НАЦИОНАЛЬНОГО ИССЛЕДОВАТЕЛЬСКОГО УНИВЕРСИТЕТА «ВЫСШАЯ ШКОЛА ЭКОНОМИКИ». РОССИЯ. Е-MAIL: aramonov@hse.ru.

ПЬЯНКОВА АНАСТАСИЯ ИВАНОВНА, ИНСТИТУТ ДЕМОГРАФИИ НАЦИОНАЛЬНОГО ИССЛЕДОВАТЕЛЬСКОГО УНИВЕРСИТЕТА «ВЫСШАЯ ШКОЛА ЭКОНОМИКИ». РОССИЯ. E-MAIL: apyankova@hse.ru

СТАТЬЯ ПОСТУПИЛА В РЕДАКЦИЮ В МАРТЕ 2014 Г.
} 
К сожалению, в современной России практика использования вопросов о здоровье в рамках переписных листов отсутствует, хотя в первых отечественных переписях (1897, 1920 и 1926 г.) содержались вопросы, направленные на оценку функциональных нарушений организма.

Появление вопросов о физических нарушениях в первых переписях населения в России соответствовало международным рекомендациям того времени. В рамках 8-ой сессии Международного статистического конгресса, проходившего в С.-Петербурге в 1872 г., был опубликован список вопросов, рекомендуемый к обязательному включению в программы переписей населения [Международный статистический конгресс 1873]. В числе одиннадцати рекомендуемых вопросов был и вопрос об отсутствии/наличии физических недостатков ${ }^{1}$.

В рамках первой переписи населения Российской Империи необходимо было поставить отметку об отсутствии/наличии физических, сенсорных (зрение, слух, речь) и умственных нарушений; лист переписи 1920 г. содержал два отдельных вопроса об отсутствии/наличии физических и психических недостатков, но характер нарушений не уточнялся; в 1926 г. формулировка вопроса была похожей, но требовалось уточнить характер недостатка и его причину [Демографический энциклопедический словарь 1985]. В рамках последующих переписей населения СССР и постсоветской России вопросы о здоровье, функциональных нарушениях здоровья не задавались.

При подготовке программы выборочного федерального статистического наблюдения «Микроперепись населения 2015» первоначально предполагалось вернуться к забытой традиции и попытаться использовать микроперепись для оценки состояния здоровья населения, распространенности функциональных нарушений и инвалидности как в целом, так и по отдельным территориальным образованиям. В эскизе программы присутствовал расширенный блок вопросов «Сведения о здоровье» [Никитина 2013]. Однако в итоге блок «Сведения о здоровье» сокращен до трех вопросов:

1. Об отсутствии/наличии зарегистрированной инвалидности.

2. Об отсутствии/наличии ограничений в жизнедеятельности из-за проблем со здоровьем.

3. О потребности в регулярной помощи/уходе со стороны других лиц.

Разумеется, переписи населения - не идеальный источник информации о здоровье. К числу их главных недостатков относится то, что они не позволяют получить детализированную картину распространенности нарушений здоровья из-за ограниченности пространства переписного листа и программы разработки результатов, а также финансовых ограничений. Помимо этого, редкая периодичность проведения традиционных переписей (раз в 10 лет согласно рекомендациям $\mathrm{OOH}$ ) не позволяет использовать их результаты для оперативного управления.

\footnotetext{
${ }^{1}$ Если человек имел физические недостатки, требовалось указать их характер. Были выделены следующие физические и психические недостатки: «слепота, глухонемота, идиотизм, кретинизм и помешательство».
} 
Все же аргументом за использование переписи для изучения здоровья является объем исследуемой совокупности. К сожалению, структуры выборок социологических обследований за редкими исключениями ${ }^{2}$ не позволяют проследить региональные особенности распространения нездоровья. Есть также и законодательные препятствия к использованию вопросов о здоровье в переписном листе (в России использование подобной информации регулируется законом «О персональных данных»).

Отдельного внимания заслуживает возможность использования в рамках переписей длинного переписного листа, предназначенного для выборочной части населения. Отказ от длинного переписного листа, куда можно было бы включить вопросы о здоровье населения, в современной российской практике не позволяет изучать более глубоко важные аспекты жизни российского общества.

В какой мере использование или неиспользование переписей населения для изучения здоровья россиян соответствует современной мировой практике? Свидетельствует ли оно об освобождении от архаики первых переписей или, напротив, об отставании от наиболее продвинутых способов их проведения?

\section{Мировой опыт использования переписей для изучения здоровья}

Для оценки опыта использования вопросов о здоровье в национальных переписях были выбраны переписные листы переписей последнего раунда 25 стран мира (США, Канада, Австралия, Новая Зеландия, Великобритания, Ирландия, Франция, Германия, Италия, Португалия, Испания, Эстония, Латвия, Литва, Польша, Болгария, Чехия, Албания, Турция, Израиль, Бразилия, Индия, Япония, Корея, Сингапур), различных по методологии проведения переписи, технологиям сбора данных и программам переписей. В обзор включены как короткие, так и длинные переписные листы, а также анкеты выборочных обследований, являющихся частью переписи в той или иной стране. Анализ переписных листов последнего раунда переписей населения показал, что в десяти из них (Канада, Франция, Германия, Латвия, Литва, Чехия, Япония, Корея, Сингапур, Албания) вопросы о здоровье не задавались ${ }^{3}$.

\footnotetext{
2 Одним из наиболее крупных обследований, репрезентирующих не только все население России, но и отдельные субъекты, стало обследование НОБУС (Национальное обследование благосостояния населения и его участия в социальных программах) — репрезентативный выборочный опрос, проведенный Госкомстатом РФ при поддержке Всемирного банка в апреле-мае 2003 г. Однако вопросник этого обследования содержал лишь общий вопрос о самооценке здоровья и регистрируемой инвалидности. Региональную дифференциацию распространенности нездоровья также позволяет провести недавно проведенное Росстатом Комплексное наблюдение условий жизни населения (2011) с объемом выборки в 10000 домохозяйств. Основные результаты опубликованы: http://www.gks.ru/free_doc/new_site/KOUZ/survey0/index.html.

${ }^{3}$ Отсутствие вопросов о здоровье в рамках переписей населения не значит, что в данных странах здоровье населения не изучается вовсе. В Канаде, Литве, Японии для этого используются выборочные обследования здоровья, возможно, именно поэтому перепись населения в этих целях не используется. Например, в Канаде до переписи 2011 г. вопросы о здоровье присутствовали в длинном переписном листе. Параллельно в стране существует система выборочных обследований здоровья, инвалидности, доступности медицинской помощи и т.д. В переписи 2011 г. длинный переписной лист как часть переписи (с обязательностью отвечать на вопросы) был отменен, его заменило добровольное выборочное обследование, не являющееся частью переписи населения.
} 
В остальных 15 странах вопрос(ы) хотя бы в одной из форм присутствуют. В двух странах вопросы задаются только в рамках длинного переписного листа (Италия, Бразилия), в США и Польше - в рамках выборочного обследования, являющегося элементом переписи населения. В остальных странах вопросы о здоровье задаются в сплошном переписном листе. В коротком переписном листе, если программа переписи предусматривает комбинацию короткого и длинного переписных листов, вопросы о здоровье не задаются.

Таким образом, изучение здоровья с помощью переписей все же достаточно распространено в мировой практике, однако содержание и формулировки задаваемых вопросов варьируются (таблица 1).

\section{Таблица 1. Распределение стран по типам вопросов о здоровье в раунде переписей} населения 2010 г.

\begin{tabular}{|c|c|c|}
\hline \multicolumn{2}{|c|}{ Тип вопроса о здоровье } & Страны и характер опроса \\
\hline \multicolumn{2}{|c|}{$\begin{array}{l}\text { Самочувствие в целом (самооценка } \\
\text { здоровья) } \\
\text { Отсутствие/наличие хронических } \\
\text { заболеваний. Длительность - как минимум } \\
\text { последние полгода. }\end{array}$} & Турция, Эстония, Новая Зеландия - сплошной опрос \\
\hline $\begin{array}{l}\text { Отсутствие/наличие } \\
\text { функциональных } \\
\text { нарушений }\end{array}$ & $\begin{array}{l}\text { без обозначения } \\
\text { вида нарушений } \\
\text { виды нарушений } \\
\text { четко обозначены в } \\
\text { вопросе или } \\
\text { варианте ответа }\end{array}$ & $\begin{array}{l}\text { Эстония, Новая Зеландия - сплошной опрос } \\
\text { США - выбборочное обследование; Ирландия -сплошной } \\
\text { опрос; Италия - длинный лист; Португалия -сплошной } \\
\text { опрос; Польша - выборочное обследование; Турция - } \\
\text { сплошной опрос; Израиль - сплошной опрос; Бразилия - } \\
\text { длинный лист; Индия - сплошной опрос }\end{array}$ \\
\hline $\begin{array}{l}\text { Уход за другими лю } \\
\text { потраченное время. }\end{array}$ & Іи, в т. ч. & Великобритания, Испания - сплошной опрос \\
\hline $\begin{array}{l}\text { Потребность в помо } \\
\text { Процент потерянной }\end{array}$ & $\begin{array}{l}\text { /уходе, ее причины } \\
\text { рудоспособности }\end{array}$ & Австралия - сплошной опрос \\
\hline $\begin{array}{l}\text { или группа инвалид } \\
\text { Нет вопросов (в кор } \\
\text { переписном листе и. }\end{array}$ & $\begin{array}{l}\text { сти } \\
\text { ком, длинном } \\
\text { выборочном }\end{array}$ & Болгария - сплошной опрос \\
\hline $\begin{array}{l}\text { обследовании, высту } \\
\text { переписи). }\end{array}$ & ющем частью & $\begin{array}{l}\text { Канада, Франция, Германия, Латвия, Литва, Чехия, Япония, } \\
\text { Корея, Сингапур, Албания }\end{array}$ \\
\hline
\end{tabular}

Источник: Составлено авторами на основе переписных листов раунда переписей населения 2010 ح.

\section{КОНЦЕПТУАЛЬНЫЕ ОСНОВЫ ФОРМУЛИРОВКИ ПЕРЕПИСНЫХ ВОПРОСОВ О ЗДОРОВЬЕ}

Как видно из таблицы 1, характер вопросов о здоровье в переписных листах (при их наличии) вариативен. Но существует ли «золотой стандарт» инструментов для измерения здоровья в рамках переписи? Обзор рекомендаций к применению определенных инструментов показал, что выбор формулировки вопросов зависит от концепции здоровья, которой придерживаются исследователи, - несколько десятилетий назад она была совершенно иной по сравнению с той, которой принято руководствоваться сегодня. 


\section{«Старая» концепция функциональных нарушений}

До 70-х - 80-х годов XX века формулировки вопросов о здоровье, задаваемых в переписях населения, опирались в большей степени на медицинскую концепцию инвалидности, которая фокусировалась на выявлении наличия заболеваний и функциональных нарушений работы организма [Nagi 1965]. Согласно этой концепции наличие ограничений ассоциировалось с чем-то внутренним и статичным, обусловленным нарушением функций организма человека и априори ему присущим. Ключевыми ее элементами стали понятия «патология» (pathology) и «нарушение функиий организма» (impairment) [Nagi 1965].

Все вариации вопросов основывались на формулировке: есть ли (и какие) у Вас нарушения? В рамках этой концепции статус инвалидности редко связывался с особенностями физического и соџиального окружения человека.

\section{«Новая» концепция ограничений в активности}

Более современные концепции здоровья во многом связаны с разработками исследователей под эгидой ВОЗ, которые берут начало в 1980-х годах. Они отражают комплексный взгляд на здоровье как социально обусловленное явление, нарушения здоровья порождаются особенностями взаимодействия индивида с физическим окружением и социальной средой. Этот подход нашел отражение в понятии «инвалидность» или «disability», отражающем «ограничения в активности» (activity restrictions), которые выражают сложную динамическую взаимосвязь между особенностями индивида (body structures, body functions) и характеристиками среды в социальном контексте (environment) [Verbrugge, Jette 1993; WHO 1980, 1998].

К примеру, индивид с серьезными нарушениями двигательного аппарата, а также речи и слуха будет на основе «старой» концепции с высокой вероятностью определен как «инвалид» или «человек с серьезными нарушениями систем организма, которые привели к его дисфункциям». В соответствии же с «новой» концепцией инвалидности он может таковым и не являться. В случае, если он пользуется усилителями слуха и зрения и дополнительным устройствами, облегчающими его передвижение, а также если физическое окружение приспособлено к его потребностям (специальные приспособления, пандусы и др.), в рамках «новой» концепции он может рассматриваться как здоровый.

С учетом этого нового подхода была принята «Международная классификация функционирования, инвалидности и нарушений здоровья» (далее МКФ), разработанная ВОЗ [WHO 1980]. Ее создание преследовало несколько целей:

1. Систематизировать заболевания и их возможные последствия для функционирования организма и жизнедеятельности.

2. Создать унифицированный терминологический аппарат и схему кодирования функциональных нарушений организма и ограничений в активности.

3. Обеспечить возможность сопоставления данных по странам и во времени.

МКФ содержит классификацию не только нарушений организма, но и ограничений в повседневной деятельности, сопряженных с ними. Пример подобной систематизации приведен в таблице 2 в отношении нейромышечных расстройств. 
Таблица 2. Разделы МКФ на примере одной патологии (пример)

\begin{tabular}{|c|c|c|c|}
\hline \multicolumn{4}{|l|}{ Болезнь: полиомиелит } \\
\hline Функции организма (Functions) & $\begin{array}{c}\text { Структура организма } \\
\text { (Structures) }\end{array}$ & $\begin{array}{l}\text { Активность } \\
\text { (Activity) }\end{array}$ & $\begin{array}{c}\text { Участие } \\
\text { (Participation) }\end{array}$ \\
\hline $\begin{array}{l}\text { Раздел 7: нейромышечные, } \\
\text { двигательные функции }\end{array}$ & $\begin{array}{l}\text { Раздел 1: структуры } \\
\text { нервной системы }\end{array}$ & $\begin{array}{l}\text { Влияет на } \\
\text { возможность }\end{array}$ & $\begin{array}{l}\text { Ограничение в } \\
\text { двигательной } \\
\text { активности мешает }\end{array}$ \\
\hline $\begin{array}{l}\text { Функции мышц (b730-b749) или } \\
\text { двигательные функции (b750-b789) }\end{array}$ & $\begin{array}{l}\text { Структура спинного } \\
\text { мозга (s1200) }\end{array}$ & $\begin{array}{l}\text { ходить или } \\
\text { подниматься по }\end{array}$ & $\begin{array}{l}\text { посещать объекты } \\
\text { социальной }\end{array}$ \\
\hline Функции мышечной силы (b730) & $\begin{array}{l}\text { Спинномозговые нервы } \\
\text { (s1201) }\end{array}$ & лестнице & $\begin{array}{l}\text { инфраструктуры } 8 \\
\text { данной среде }\end{array}$ \\
\hline
\end{tabular}

Последняя редакция принципов и рекомендаций ООН в отношении проведения переписей населения и жилищного фонда (далее Принципы и рекомендации) содержит 9 тематических блоков вопросов, рекомендуемых для включения в переписи населения [ООН 2009]. Блок №8 посвящен вопросам об инвалидности. Использованная при его разработке концепция инвалидности основывается на МКФ и работах Вашингтонской группы (ВГ) по статистке инвалидности, являющейся подразделением Центра по контролю и профилактике заболеваний (CDC).

Усилиями этой группы сформулирован ряд направлений использования результатов оценки здоровья на основе переписи населения:

1. Разработка специальных программ с учетом потребностей людей с функциональными нарушениями в услугах: жилье, транспорте, вспомогательных технологиях, профессиональном уходе, долгосрочном уходе и т.д.

2. Мониторинг уровня распространения ограничений: оценка и анализ тенденций.

3. Оценка неравенства возможностей осуществления полноценной социальной жизни среди населения с функциональными нарушениями.

Достижение последней цели представляется наиболее реалистичным именно с помощью переписей.

Эволюцию концепции здоровья можно проследить по истории постановки вопросов о здоровье в переписях населения США. Первый раз вопросы о здоровье появились в переписных листах в 1830 г., их постановка предвосхитила рекомендации восьмой сессии Международного статистического конгресса. Перепись 1890 г. отличалась «некоторой своеобразной постановкой вопросов о здоровье» - была введена графа, требующая отметить «страдает ли какими-нибудь острыми или хроническими болезнями, указать их название и продолжительность» [Урланис 1938]. Программа переписей населения США 1890 г. одна из первых содержала вопросы о здоровье в рамках «медицинской» концепции, но это был первый и единственный опыт постановки вопроса подобным образом в переписях населения. После этого вплоть до 1970 г. вопросы о здоровье в рамках переписей в этой стране не задавались.

Новым этапом стала перепись 1970 г., в рамках которой был предусмотрен длинный опросный лист для 5\% населения, содержащий вопросы о здоровье. Формулировка этих вопросов была совершенно иной, нежели прежде. Требовалось ответить положительно или 
отрицательно на вопрос: есть ли у респондента какие-либо физические или психические болезни, ограничивающие длительность и характер paботы, которую он может выполнять? В последующих переписях вопрос ставился именно таким образом, перечень сфер жизненной активности расширялся. Так, в раунде переписей 2000 г. в США и Канаде изучалось отсутствие/наличие ограничений в активности на работе, дома, при посещении социильных учреждений, в том числе школь, при пользовании транспортом. В США требовалось указать только наличие или отсутствие указанных ограничений (вопросы 1617 переписного листа), в Канаде - степень ограничения в активности («иногда», «часто», «отсутствие ограничений»). ${ }^{4}$

\section{ИЗМЕРЕНИЕ ОГРАНИЧЕНИЙ В АКТИВНОСТИ: РЕКОМЕНДАЦИИ ВАШИНГТОНСКОЙ ГРУППЫ}

В 2001 г. состоялся Международный семинар ООН по измерению нарушений здоровья и инвалидности. По его итогам для решения задачи внедрения и унификации инструментария измерения инвалидности в рамках переписей и национальных обследований статистическая комиссия ООН санкционировала создание Вашингтонской группы (далее ВГ). Ее задачей стало взаимодействие с представителями национальных статистических служб, предложения и контроль эффективности использования инструментария для измерения здоровья в соответствии с рекомендациями ООН.

В 2006 г. усилиями ВГ был разработан краткий перечень вопросов, предлагаемый для включения в переписи населения, и длинный список, предназначенный для выборочных обследований. Опираясь на рамки, заданные МКФ, ВГ ставила перед собой задачу выявить группы населения, испытывающие «ограничения в активности» (activity restrictions) как в повседневной деятельности, так в общественной жизни в связи с какимилибо проблемами со здоровьем (заболеваниями).

К видам ограничений в активности, соответствующим определенным функциональным нарушениям организма, относятся: а) нарушения зрения (при условии пользования очками); б) нарушения слуха (при условии пользовании слуховым аппаратом); в) трудности при передвижении (подъем по лестнице или ходьба); г) проблемы с концентрацией и памятью; д) сложности с самообслуживанием (одевание, прием душа); е) сложности с пониманием. Для каждого из этих вопросов предлагается 4 альтернативы ответа: 1) Отсутствуют затруднения; 2) Есть некоторые затруднения; 3) Есть серьезные затруднения; 4) Не могу делать самостоятельно [Washington Group 2009].

На основе анализа распределений ответов на эти вопросы ВГ предлагает «индекс инвалидности». В соответствии с его значениями, человек может быть с большей вероятностью, чем другие, отнесен к группе людей с нарушениями активности и рассчитывать на социальную помощь, если он имеет серьезные затруднения или не может выполнять самостоятельно (альтернативы 3 или 4) хотя бы одну из указанных функций.

4 Департамент статистики ООН: Список вопросов для измерения инвалидности, 2001. http://unstats.un.org/unsd/demographic/sconcerns/disability/disabmethods.aspx?id=Canada. 
Внедрение усилиями ВГ в национальные переписи населения ряда стран нового подхода к измерению инвалидности, отражающего комплексный взгляд на инвалидность, показало более высокий уровень ее распространенности по сравнению с измеренной на основе показателей медицинской концепции (наличие или отсутствие нарушений, заболеваний).

По данным обследований жилищных условий в Замбии в 2006 г., распространённость инвалидности, если ее рассматривать как наличие некоторых вымеупомянутых ограничений хотя бы по одному виду базовой активности, составила $14,35 \%$. При учете только серьезных ограничений хотя бы по одному виду базовой активности этот показатель составил 8,5\%. В то же время доля ответивших положительно на вопрос «Имеется ли у Вас инвалидность?» в том же году составила лишь 2,7\% [Washington Group 2009].

Наличие предложенного ВГ блока вопросов позволяет специфицировать инвалидность по сферам жизненной активности, изучаемым в рамках большинства переписей населения: образование, экономическая деятельность. Принципы и рекомендации содержат следующие примеры таблиц, рекомендуемых для разработки данных по инвалидности:

1. Все население с разбивкой по наличию или отсутствию инвалидности (статусу инвалидности), возрасту и полу.

2. Все население в возрасте 5 лет и старше с разбивкой по статусу инвалидности, уровню образовательной подготовки, возрасту и полу.

3. Население в возрасте ... лет ${ }^{5}$ и старше с разбивкой по статусу инвалидности, статусу текущей (или обычной) экономической активности, возрасту и полу.

ВГ ежегодно отслеживает распространенность и характер использования короткого вопросника в переписях и обследованиях по разным странам. Собираемая информация касается того, где и как задавались вопросы, в какой форме, почему не задавались, планируется ли внедрение полученных результатов в дальнейшем и в какой форме. Ниже представлены данные опроса представителей статистических ведомств ряда стран (38 в 2011 г. и 42 в 2012 г.), которые согласились сотрудничать с ВГ.

Как видно на рисунке 1, выборочные обследования здоровья сегодня в большинстве стран используются для оценки распространенности инвалидности все же более часто, чем переписи населения. Это связано с уже обозначенными преимуществами выборочных обследований. Второй распространенный способ сбора данных об инвалидности - это сочетание результатов выборочных обследований и данных текущего учета (данных медицинских и медико-социальных учреждений). Данные текущего учета (административные) как единственный источник информации об инвалидности используются относительно редко.

\footnotetext{
${ }^{5}$ Минимальный возраст, принятый в стране для подсчета экономически активного населения. 


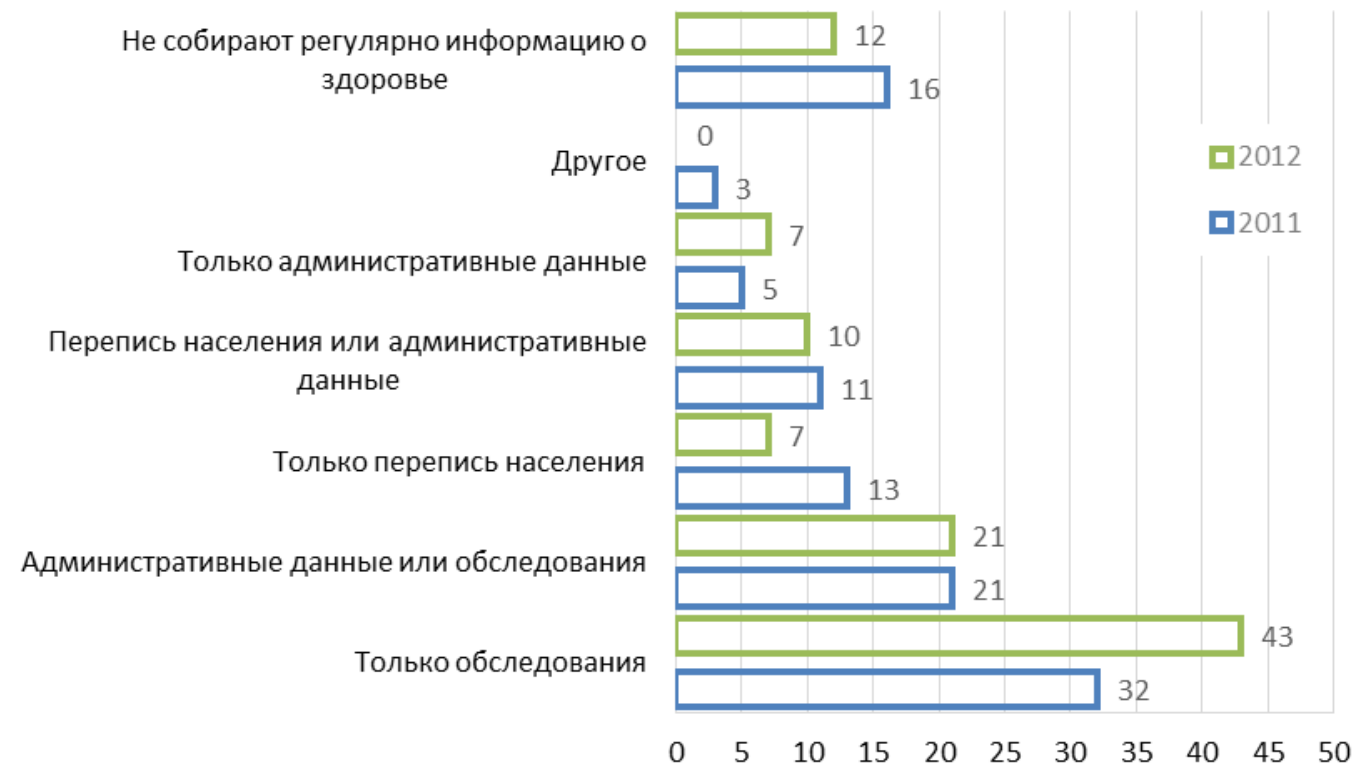

\section{Рисунок 1. Распределение стран мира, предоставивших отчеты ВГ, по способам сбора информации об инвалидности, \%}

Источник: Составлено по презентациям Cordell Golden за 2011-2012 г2. на встречах ВГ по cтатистике инвалидности. URL: http://www.cdc.gov/nchs/washington_group/wg_meetings.htm. Примечание: Число стран, ответивших на вопросы обследования: в 2011 г. - 38, в 2012 г. - 42.

Намерения включить короткий список вопросов в переписной лист и их реализация существенно различаются - только половина стран, собиравшихся включить данные вопросы в программу переписи населения, сделали это в раунде переписей населения 20102011 гг. (таблица 3).

Таблица 3. Распределение ряда стран мира по планам включения короткого списка вопросов ВГ об инвалидности в национальные переписи населения и реализации этих планов

\begin{tabular}{l|c|c|c}
\hline & Будет ли включен, \% & \multicolumn{2}{|c}{ Был ли включен, \% } \\
\cline { 2 - 4 } & 2010 & 2011 & 2012 \\
\hline \multirow{2}{*}{ Да } & 45,6 & 26,3 & 26 \\
Нет & 43,5 & 68,4 & 69 \\
Нет ответа & 10,8 & 5,3 & 5 \\
\hline
\end{tabular}

Источник: Составлено по презентациям Cordell Golden за 2010-2012 г2. на встречах ВГ по статистике инвалидности. URL: http://www.cdc.gov/nchs/washington_group/wg_meetings.htm. Примечание: Число стран, ответивщих на вопросы обследования: в 2011 г. - 38, в 2012 г. - 42.

Основные причины, по которым вопросы не были включены в переписные листы: наличие других источников данных, на основе которых определяется статус инвалидности, и необходимость соблюдать преемственность с прежними схемами сбора данных с целью сопоставимости. Несмотря на то, что эти две причины достаточно устойчиво находятся в начале списка, в 2012 г. увеличилось число стран, планирующих включить вопросы об инвалидности в переписные листы (рисунок 2). 


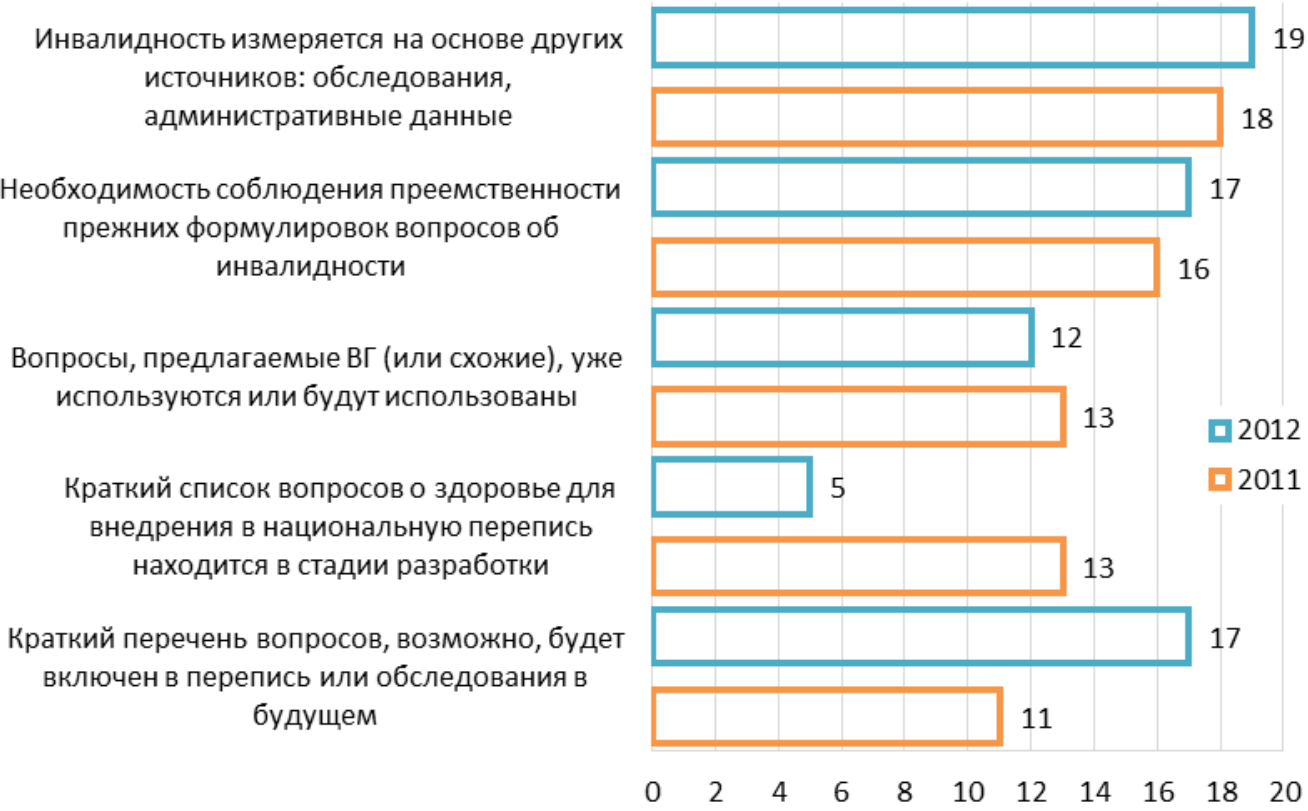

Рисунок 2. Причины неиспользования вопроса об инвалидности в форме, предлагаемой ВГ и Принципами и рекомендациями ООН, при переписях населения раунда 2010 г., \%

Источник: Составлено по презентаџиям Cordell Golden за 2011 и 2012 г. на встречах ВГ по статистике инвалидности.

Примечание: На рисунке указаны первые пять причин, на которые указали 4 и более страны. Всего было указано 11 причин. Число ответивших стран: в 2011 г. - 38, в 2012 г. - 42.

\section{ВОПРОСЫ ДЛЯ ИЗМЕРЕНИЯ ОГРАНИЧЕНИЙ В АКТИВНОСТИ СОГЛАСНО РАСШИРЕННОЙ ТРАКТОВКЕ ВОЗ}

Упомянутый выше предложенный набор из трех вопросов о здоровье программы российской микропереписи 2015 г. не позволяет получить полноценную картину ограничений в активности (disability), детализированную по специфике нарушений в соответствии с концепцией МКФ и рекомендациями ВГ, поскольку носит слишком общий характер.

В дальнейшем с целью получения более детализированной картины инвалидности с помощью длинного листа переписи и/или микропереписи населения России на основе рекомендаций ООН и ВГ можно предложить набор из следующих четырех вопросов. Они частично пересекаются с уже предложенными тремя вопросами, но в них заложено расширенное понимание форм и причин ограничений в активности.

№1. Испытываете ли Вы затруднения в обычной повседневной деятельности из-за проблем со здоровьем (на протяжении как минимум последнего полугодия)?

Да, незначительные... 1

Да, серьезные затруднения...2

Нет...3

Затруднение/отказ...9 


\section{№2. Имеются ли у Вас следующие нарушения, препятствующие выполнению повседневных дел?}

- $\quad$ Нарушения зрения при использовании очков или контактных линз. Hanpuмep, Bbl не можете прочитать шрифт стандартной статьи в газете или журнале, даже если надеты очки.

$$
\begin{aligned}
& \text { Да, иногда...1 } \\
& \text { Да, часто...2 } \\
& \text { Нет...3 }
\end{aligned}
$$

- $\quad$ Нарушения слуха (при использовании слухового аппарата). Например, Bbl не можете рассльшиать всего сказанного, общаясь на улице с двумя другими собеседниками, даже если используете слуховой аппарат.

$$
\begin{aligned}
& \text { Да, иногда...1 } \\
& \text { Да, часто....2 } \\
& \text { Нет...3 }
\end{aligned}
$$

- $\quad$ Проблемы с концентрацией внимания и запоминанием информации для решения повседневных задач.

$$
\begin{aligned}
& \text { Да, иногда...1 } \\
& \text { Да, часто...2 } \\
& \text { Нет...3 }
\end{aligned}
$$

- $\quad$ Трудности при передвижении. Например, Вы не можете самостоятельно подняться (или спуститься) на несколько этажей по лестнице.

Да, иногда...1

Да, часто...2

Нет...3

- $\quad$ Постоянные боли (на протяжении нескольких дней как минимум).

$$
\begin{aligned}
& \text { Да, иногда...1 } \\
& \text { Да, часто...2 } \\
& \text { Нет...3 }
\end{aligned}
$$

- Ничего из вышеперечисленного

- Затруднение/отказ

№3. Испытываете ли Вы затруднения при самообслуживании? (к примеру: принять душ, воспользоваться туалетом, одеться, самостоятельно выйти на улииу)?

Интервьюер: Имеются в виду ограничения длительностью не менее 6 месяцев.

$$
\begin{aligned}
& \text { Да...1 } \\
& \text { Нет...2 } \\
& \text { Не могу делать самостоятельно...3 } \\
& \text { Затруднение/отказ...9 }
\end{aligned}
$$

№4. Для тех, кто вылбрал альтернативу 1 или 3 в предыдущем вопросе. Необходима ли вам регулярная помощь другого человека или вспомогательные устройства (например, кресло, трость) при выполнении повседневных действий, связанных с самообслуживанием?

Да, нужны специальные устройства (инвалидное кресло, трость) ...1

Да, нужны специальные устройства и регулярная помощь

окружающих...2

Нет...3

Затруднение/отказ...9 
В таблице 4 показано отношение, которое имеют предложенные вопросы о здоровье и инвалидности (все вопросы, кроме №4) к структурным элементам модели МКФ ВОЗ и к краткому перечню вопросов ВГ.

\section{Таблица 4. Рекомендованные вопросы по измерению здоровья и рекомендации Вашингтонской группы и ООН}

\begin{tabular}{|c|c|c|c|}
\hline Вопрос & $\begin{array}{c}\text { Измеряемый } \\
\text { компонент } \\
\text { МКФ ВОЗ } \\
\end{array}$ & $\begin{array}{c}\text { Соответствие } \\
\text { рекомендациям ВГ }\end{array}$ & $\begin{array}{c}\text { Соответствие } \\
\text { рекомендациям ООН }\end{array}$ \\
\hline $\begin{array}{l}\text { №1. Ограничения в } \\
\text { повседневной } \\
\text { деятельности }\end{array}$ & $\begin{array}{l}\text { Активность } \\
\text { (activity) } \\
\text { Участие } \\
\text { (participation) }\end{array}$ & $\begin{array}{l}\text { В кратком перечне вопросов } \\
\text { ВГ не содержится, но } \\
\text { рекомендован к } \\
\text { использованию в } \\
\text { национальных } \\
\text { обследованиях Евростатом }\end{array}$ & $\begin{array}{l}\text { Общий вопрос об } \\
\text { ограничениях с } \\
\text { разделением степени их } \\
\text { тяжести, длительностью } \\
\text { не менее полугода }\end{array}$ \\
\hline $\begin{array}{l}\text { №2. Функциональные } \\
\text { нарушения }\end{array}$ & $\begin{array}{l}\text { Функциональные } \\
\text { нарушения (body } \\
\text { functions) } \\
\text { Активность } \\
\text { (activity) }\end{array}$ & $\begin{array}{l}\text { Содержит в качестве } \\
\text { альтернатив набор действий, } \\
\text { указанные в вопросах 1-4 } \\
\text { краткого перечня вопросов } \\
\text { ВГ}{ }^{6} . \text { В качестве альтернатив } \\
\text { представлены основные } \\
\text { функциональные сферы } \\
\text { жизнедеятельности на } \\
\text { основе концепции МКФ } \\
\text { ВОЗ. }\end{array}$ & $\begin{array}{l}\text { В соответствии с } \\
\text { рекомендациями ООН } \\
\text { учитываются серьезные } \\
\text { нарушения (не } \\
\text { поддающиеся полной } \\
\text { коррекции } \\
\text { вспомогательными } \\
\text { приборами) } \\
\text { В соответствии с } \\
\text { рекомендациями ООН не } \\
\text { измеряются когнитивные } \\
\text { нарушения в связи со } \\
\text { сложностью и } \\
\text { комплексностью понятия }\end{array}$ \\
\hline $\begin{array}{l}\text { №3. Ограничения при } \\
\text { самообслуживании }\end{array}$ & $\begin{array}{l}\text { Активность } \\
\text { (activity) }\end{array}$ & $\begin{array}{l}\text { Ограничения при } \\
\text { выполнении повседневных } \\
\text { операций, самые тяжелые }\end{array}$ & $\begin{array}{l}\text { Учитываются серьезные } \\
\text { ограничения, } \\
\text { длительностью не менее } \\
\text { полугода }\end{array}$ \\
\hline
\end{tabular}

Первый вопрос, также известный как Global Activity Limitation Indicator, применяется в обследованиях по всему миру, в частности, для последующей оценки ожидаемой продолжительности здоровой жизни ${ }^{7}$.

Второй вопрос касается функциональных нарушений, препятствующих осуществлению повседневной деятельности. В соответствии с рекомендациями ООН и ВГ он содержит спецификацию по областям деятельности с учетом ключевых функций организма, которые отвечают за деятельность в этих областях. В том или ином виде этот вопрос включен в опросные листы переписей большинства рассматриваемых стран. Эти же составляющие используются в международной практике оценки здоровья на основе индексов качества жизни. При этом речь идет о тяжелых ограничениях (даже при условии,

\footnotetext{
${ }^{6}$ Census Questions on Disability Endorsed by the Washington Group. Доступно для скачивания на сайте Вашингтонской Группы: http://www.cdc.gov/nchs/data/washington_group/WG_Short_Measure_on_Disability.pdf.

7 Организации Евростат и JA-EHLEIS производят регулярную оценку этих показателей в странах ЕC, известных также как Healthy Life Years.
} 
что такие ограничения могут быть частично устранены с помощью вспомогательных устройств).

Третий вопрос необходим для оценки затруднений при выполнении повседневных операций из-за проблем со здоровьем. Принимаются во внимание только долговременные ограничения (длительностью не менее 6 месяцев).

Четвертый вопрос необходим для оценки потребности в социальной помощи (поэтому не вошел в таблицу) для тех людей, которые указали на наличие ограничений в предыдущем вопросе.

В рамках утвержденного листа российской микропереписи 2015 г. $^{8}$ сохранились только первый и четвертый вопросы. Присутствие вопроса №2 и в длинном листе переписи (при наличии такового), и в микропереписи, как было отмечено, позволило бы получать более детализированную информацию о состоянии здоровья.

Разработка содержания программы, будь то перепись населения или специализированное обследование здоровья, должна вестись с учетом наличия уже существующей информации в административных и ведомственных источниках данных в целях избегания дублирования. С другой стороны, такое дублирование может быть использовано в целях взаимной проверки и совершенствования самих процедур учета (в частности, освидетельствования инвалидности бюро медико-социальной экспертизы).

$$
* * *
$$

Использование преимуществ каждого элемента системы источников данных о здоровье населения и их интеграция позволили бы создать комплексную систему показателей здоровья, собираемых из взаимодополняющих источников и измеряемых на регулярной основе. Это сделало бы возможным оценку, в частности, интегральных мер здоровья, необходимых для разработки политики системы здравоохранения и принятия решений о пенсионном возрасте [Рамонов 2013]. Предложенные рекомендации по совершенствованию методологии переписи населения РФ и внедрению в переписные листы используемых в мировой практике вопросов позволят более обоснованно и взвешенно принимать политические решения, опираясь на оперативный мониторинг здоровья населения.

\section{ЛИТЕРАТУРА}

Демографический энциклопедический словарь (1985) / Под ред. Д.И. Валентея. М.: Советская Энциклопедия.

Международный статистический конгресс (1873). Сессия 8. Доклады и постановления. Спб.: 1873.

Никитина С.Ю. (2013). Об организационных и методологических вопросах выборочного федерального статистического наблюдения «Микроперепись 2015 г.» // Презентация

8 Формы опросных листов федерального статистического наблюдения "Социально-демографическое обследование (микроперепись населения) 2015 года» утверждены приказом Росстата от 22.04.2014 № 267. 
доклада начальника управления статистики населения и здравоохранения на расширенном заседании коллегии Росстата 12.02.2013 г. URL:

http://www.gks.ru/free_doc/new_site/rosstat/smi/smi-1302.html (дата обращения: 21.07.2014).

Принципы и рекомендации в отношении переписей населения и жилого фонда (2009). Второе пересмотренное издание. Нью-Йорк: ООН.

Рамонов А.В. (2013). Система интегральных показателей здоровья населения: методология анализа и возможности применения в России. Диссертация на соискание ученой степени кандидата социологических наук. Москва: НИУ ВШЭ.

Урланис Б.Ц. (1938). История американских цензов. М.: Госпланиздат.

Iezzoni L. (2011). Eliminating health and health care disparities among the growing population of people with disabilities // Health Aff. 30:1947-1954.

Mishra A., R. Gupta (2006). Disability Index: A measure of deprivation among the elderly // Economic and Political Weekly 41(38).

Nagi S.Z. (1965). Some conceptual issues in Disability and Rehabilitation // M. Sussman, ed. Sociology and Rehabilitation. Washington, DC: American Sociological Association.

Verbrugge L.M., A.M. Jette (1993). The disablement process // Social science and medicine $6(1)$

Washington Group on Disability Statistics (2009). Understanding and Interpreting Disability as Measured using the WG Short Set of Questions. URL:

http://www.cdc.gov/nchs/washington_group/wg_documents.htm (дата обращения: 21.07.2014).

WHO (1980). International Classification of Impairments, Disabilities, and Handicaps: a manual of classification relating to the consequences of diseases. Geneva: World Health Organization.

WHO (1998) Health 21. An introduction to the health for all policy framework for the WHO European Region. Copenhagen: World Health Organization Regional Office for Europe. 


\section{EVALUATING PUBLIC HEALTH ON THE BASIS OF CENSUS INFORMATION}

\section{Alexander Ramonov, Anastasia Pyankova}

Alexander Ramonov, Institute of Demography, National Research University Higher School of ECONOMICS. E-MAIL: aramonov@hse.ru.

Anastasia Pyankova, Institute of Demography, National Research University Higher School of ECONOMICS. E-MAIL: apyankova@hse.ru.

DATE RECEIVED: MARCH 2014.

The article looks at key approaches to population health and disability analysis. It demonstrates the fruitfulness of the "modern" conception of disability understood as restrictions on daily life activities due to health problems, and proposes instruments for measuring public health and disabilities in Russia based on international experience using the census and census-based surveys. Specifically, it applies WHO and UN recommendations to the micro-census of 2015 to develop tools for getting more detailed and useful information on disability than is currently available.

Key words: census, population health, disability.

\section{REFERENCES}

Iezzoni L. (2011). Eliminating health and health care disparities among the growing population of people with disabilities // Health Aff. 30:1947-1954.

Mezhdunarodnyi statisticheskyi congress [International statistical congress] (1873). Sessiya 8: Doklady i postanovleniya [Session 8. Reports and resolutions.]. Sankt-Peterburg.

Mishra A., R. Gupta (2006). Disability Index: A measure of deprivation among the elderly // Economic and Political Weekly 41(38).

Nagi S.Z. (1965). Some conceptual issues in Disability and Rehabilitation // M. Sussman, ed. Sociology and Rehabilitation. Washington, DC: American Sociological Association.

Nikitina S. (2013). Ob organizacionnyh i metodicheskih voprosah vyborochnogo federalnogo statisticheskogo nabludeniya «Microperepis' 2015» [Methodological and organizational questions of federal sample survey «Microcensus 2015»] // Prezentaciya doklada na rasshirennom zasedanii kollegii Rosstata 12.02.2013 [Presentation of head of public health department Rosstat 12.02.2013]. URL: http://www.gks.ru/free_doc/new_site/rosstat/smi/smi1302.html (accessed: 21.07.2014).

Principy i recomendacii $v$ otnoshenii perepisey zhilogo fonda [Census methodology foundations and recommendations] (2009). Vtoroe peresmotrennoe izdanie [The second re-esited version]. New York: UN.

Ramonov A.V. (2013). Sistema integral'nyh pokazateley zdorovya naseleniya: metodologiya analiza i vozmozhnosti primeneniya $v$ Rossii [Summary population health indicators in the Russian Federation: methodology and measurement design]. Dissertaciya [dissertation]. Moscow: HSE.

Urlanis B. (1938). Istoriya Amerikanskih censov [The History of American censuses]. M.: Gosplanizdat.

Valentey D., ed. (1985). Demograficheskiy Enciklopedivheskiy Slovar' [Encyclopedia of demography]. Moskva: Sovetskaya Enciklopedia. 
Verbrugge L.M., A.M. Jette (1993). The disablement process // Social science and medicine $6(1)$.

Washington Group on Disability Statistics (2009). Understanding and Interpreting Disability as Measured using the WG Short Set of Questions. URL:

http://www.cdc.gov/nchs/washington_group/wg_documents.htm (accessed: 21.07.2014).

WHO (1980). International Classification of Impairments, Disabilities, and Handicaps: a manual of classification relating to the consequences of diseases. Geneva: World Health Organization.

WHO (1998) Health 21. An introduction to the health for all policy framework for the WHO European Region. Copenhagen: World Health Organization Regional Office for Europe. 